\title{
A.JO'ГE
}

African Journal of Teacher Education

ISSN 1916-7822. A Journal of Spread Corporation

Volume 10. No. 12021 Pages 127-152

\section{Symbolic Representations as Teachers Reflect on Inclusive Education in South Africa}

\author{
Elizabeth Hooijer, Martyn Van Der Merwe, \& Jean Fourie \\ University of Johannesburg \\ Faculty of Education \\ South Africa
}

\begin{abstract}
The inclusive education movement generated many changes in the education system worldwide, resulting in teachers needing to change their practice and beliefs and implement inclusive teaching strategies to accommodate a more diverse learner population. Numerous professional development courses were conducted in South Africa, however the expected change in attitude and practice proved difficult to achieve for many. Even after attending such courses, teachers found it challenging to establish inclusive learning environments, believing they did not have the necessary skills and resources to teach learners with divergent learning needs. This study explored the pivotal role of teachers and their personal perspectives of themselves as inclusive practitioners in South Africa after attending a professional development course on inclusive education strategies. A qualitative, interpretative research design was utilised whereby visual symbols alongside written reflections were analysed to identify changes in teachers' knowledge, beliefs and practice. Findings revealed that teachers' knowledge had increased, their attitudes towards learners with diverse needs was more positive, they felt more confident in their own abilities and more equipped for the task. Critical reflection emerged as an essential skill for teachers to be able to question their beliefs and rethink their practice but that this skill needed to be actively taught and encouraged in order to change prevailing perceptions of diversity and improve teaching practice.
\end{abstract} Keywords: attitudes, critical reflection, inclusive teaching strategies, knowledge, practice, visual symbols 


\section{Introduction}

Whenever there are changes made to current education policy in any education system, these changes need to be communicated to all relevant role players. This is usually done through the conducting of continuing professional development courses (CPD) especially for in-service teachers to inform them of the new policy expectations (Darling-Hammond et al., 2017) CPD courses usually have two broad objectives; firstly, to impart changes in policy to practising teachers and secondly to initiate change in teachers' knowledge and skills as well as their attitudes, beliefs and values regarding the envisaged educational reforms (Guskey, 2002).The inclusive education movement, inspired by the resolutions taken in Salamanca, changed the education environment significantly in many countries (Braunsteiner, 2016). As classrooms became increasingly diverse and learners with different cultural, ethnic, economic and learning abilities were included in mainstream schools, many CPD programmes relating to inclusive education were conducted. The assumption being that after attendance at a CPD training course on inclusion, teachers would be able to change their initial perceptions and beliefs concerning diversity in the classroom and become more inclusive in their teaching practice (Engelbrecht, Nel, Nel, \& Tlale, 2015; Guskey, 2002). Numerous research studies attest to the fact that while most in-service teachers were accepting of the premise of inclusive education, they still lacked knowledge and skills and self-efficacy in their ability to work confidently with diverse learners (Donahue \& Borman, 2014; Engelbrecht, Nel, Smit, \& van Deventer, 2015; Forlin \& Sin, 2017; Rouse, 2008; Swart, et al., 2002). Pantic and Florian (2015) have argued that the manner in which teachers address learner diversity in inclusive classrooms appears to be dependent on their knowledge, attitudes and beliefs, their school context and resources as well as the practical strategies they employ and that these are the determining factors in becoming inclusive practitioners. Since schools have been touted as being the best vehicle to change attitudes towards people living with disability, it follows that teachers' attitudes are important as teacher attitudes directly influence and impact the attitudes of the learners they teach (Dreyer, 2017).

In South Africa, the promulgation of the new Constitution in 1996 set the stage for the transformation of the education system. The aim was to encourage social justice and promote diversity to redress the inequity of the previous regime, hence various legislation was introduced to change the existing system into one based on the philosophy of inclusion. The real journey into inclusive education began with the introduction of Education White Paper 6 (EWP 6) in 2001 
(DoE, 2001), which sought to address a wide range of learning needs within regular classrooms, promote diversity and create a safe learning environment for all learners. Strategic objectives were identified in all areas to move towards a more inclusive education system that would provide quality education to all learners, especially for those learners who had previously been excluded from the system. However, the years since the promulgation of EWP 6 have placed significant demands on teachers. Not only have teachers needed to change in order to fit in with the transformation of the education system into a more just and equitable system in response to previous injustice, they have also had to adjust to new policies, curricula and diverse classrooms with learners with different disabilities needing to be accommodated. One of the defining features of an inclusive education and training system according to EWP 6 is the "changing of attitudes, behaviour, teaching methodologies, curricula and the environment to meet the needs of all learners" (DoE, 2001 p. 16). A number of research studies have likewise reported that teachers in South Africa agree that all learners have the right to access quality education and that the philosophy of inclusive education promotes the principles of social justice and human rights. Nevertheless, this acceptance of the ideals and values of inclusion has not always translated into practice. The prevailing attitudes in many schools has remained less positive towards learners with disabilities and diverse learning needs. Negative perceptions and prejudice persist in many communities due to lack of knowledge, discriminatory attitudes and even superstition around disability (Rieser, 2013). Deficit thinking appears to be still deeply ingrained in some teachers contributing to their beliefs that they are not able to teach learners with disabilities (DBE, 2016). This has unfortunately led in some cases to an attitude of hopelessness and even to a rejection of inclusive teaching practices by some teachers (Oswald \& Swart, 2011).

For the vision of an inclusive education system to become a reality, education departments around the world realised they would have to develop a multifaceted approach which would enable all schools to recognise the learning potential of every child as well as accommodate a wide range of learning needs. In particular, in-service teachers would need to be convinced to become more inclusive in their attitudes and teaching practice (Pantic \& Florian, 2015). 


\section{The important role of teachers}

Different research studies have acknowledged the role of teachers worldwide as being paramount to the success of the implementation of inclusive education and the transformation of the education system (Donohue \& Bornman, 2014; Engelbrecht, Nel, Nel, \& Tlale, 2015; Pantic \& Florian, 2015). Therefore, in order to realise transformation, the pivotal role of teachers was recognised and numerous training courses have been conducted to inform and support teachers in their understanding of inclusive education and the sharing of best practice to accomplish a more inclusive education system (Walton, 2010).

Different research studies have acknowledged the role of teachers worldwide as being paramount to the success of the implementation of inclusive education and the transformation of the education system (Donohue \& Bornman, 2014; Engelbrecht, Nel, Nel, \& Tlale, 2015; Pantic $\&$ Florian, 2015). Therefore, in order to realise transformation, the pivotal role of teachers was recognised and numerous training courses have been conducted to inform and support teachers in their understanding of inclusive education and the sharing of best practice to accomplish a more inclusive education system (Walton, 2010).

The role of inclusive teachers encompasses being able to effectively support learners with diverse learning needs through the development of inclusive teaching practice and strategies thus, improving overall achievement. Moreover, this role also comprises the development of social justice, the creation of an inclusive environment, collaboration with all stakeholders and the development of their capacity to reflect on their own inclusive practice (Engelbrecht, Nel, Nel, \& Tlale, 2015; Guskey, 2002; Pantic \& Florian, 2015). Without the 'buy in' of teachers, the creation of a more inclusive and equitable education system that could reasonably accommodate all learners would not be possible. It has been asserted that in combination with providing teachers with the necessary knowledge and skills to become more inclusive in their practice, it is just as important to instil the appropriate beliefs and attitudes to realise a commitment to teaching inclusively (Forlin $\&$ Sin, 2017; Nel et al., 2016). Education authorities can develop and legislate changes in policy but it is far more difficult to change the existing attitudes of in-service teachers (Madikana et al., 2007). The attitudes of in-service teachers and their beliefs around inclusive practices within their own schools and classrooms is one of the most important factors to consider when planning CPD training courses in inclusive education. Moreover, the attitude of teachers' towards implementing 
inclusive practices in their classrooms is also influenced by their peculiar systemic contextual factors (Engelbrecht, Nel, Nel, \& Tlale, 2015). High quality CPD courses should consider the context of the cohort of teachers attending a specific CPD course and ensure that the content being presented is pertinent to that context if the training is to be successful in changing the attitudes of in-service teachers (Darling-Hammond et al., 2017).

Developing an inclusive culture within schools whereby diversity is valued and all teachers and learners are supported, is frequently influenced by the existing attitude at any school (Donohue \& Bornman, 2014). However, at the time inclusive education was implemented, most practising in-service teachers had been trained with a view to teaching in a general education classroom from which children with any type of disability were usually excluded. Teachers were predisposed to medical-model thinking in that learners with any special educational needs or learning barriers were to be placed in specialised schooling environments and taught by teachers specially trained to manage such learning needs. These long-standing misconceptions about disability and the achievement potential of learners with disabilities needed to be confronted. Therefore, the essence of many publications and CPD training courses on inclusion, was to initiate change in teacher's attitudes and beliefs from the medical model of thinking about learners with learning barriers to a more social rights or inclusive model of supporting all learners under the principle of normalisation (Hehir et al., 2016). Central to such training courses was an underlying assumption that expounding an inclusive philosophy and good teaching practice would be accompanied by a change in thinking about disability leading to acceptance of diversity and positive outcomes for all learners as teachers became more inclusive and reflective practitioners (Forlin \& Sin, 2017). However, this has proved to be a daunting task as although many teachers have been exposed to CPD courses on inclusion, mere exposure to new knowledge has proved insufficient in transforming attitudes and teaching practice. In part this has been attributed to the initial teacher training which tended to promote deficit model thinking particularly in South Africa (Engelbrecht, Nel, Nel, \& Tlale, 2015). Other research studies report that the response from teachers has largely been one of feeling unprepared and unqualified to teach learners with disabilities, resulting in poor implementation of inclusive teaching practices and little change in their beliefs and thinking about disability (Hehir et al., 2016). The implementation of inclusive education practices in South African schools has been hampered by a lack of teacher skills and adequate training (Dalton et al., 
2012), a lack of clarity in educational policies, negative attitudes and inadequate resources (Donohue \& Bornman, 2014). Some studies have reported that while teachers have indicated an improved understanding of the precepts of inclusive education this has not necessarily translated into a more empathetic understanding of disability or the accommodation of learners with different learning needs in general education classrooms (Madikana et al., 2007; Rouse, 2008; Muzata, 2021). However, if in-service teachers receive good, practical training in inclusion and inclusive teaching practices, this can have a positive effect on their attitudes towards including learners with different education needs successfully in their classrooms. With appropriate training, teachers can develop positive attitudes toward learners with diverse abilities, realise they have agency in being able to use the skills they already possess and improve their teaching practice ensuring constructive learning outcomes for all learners (Forlin \& Sin, 2017, Muzata \& Ndonyo, 2019).

To this end many research studies on inclusive education and practice found that shortterm further training for in-service teachers is largely ineffective as change in attitude is difficult to accomplish and is often a long-term process (Darling-Hammond et al., 2017). Liu (2013) proposes that transformative learning resulting in a change of teacher's attitude and behaviour can be developed through cultivating the habit of critical reflection. While there is much debate on what critical reflection means, the construct is usually associated with thinking about the assumptions that teachers make about teaching, their beliefs about those assumptions and being able to question how they act on those assumptions in the classrooms (Mezirow, 1997).

\section{Critical reflection skills for teachers}

To enable teachers to work effectively in diverse classrooms, a number of aspects are involved. These include imparting theoretical knowledge about inclusive teaching methodologies, encouraging and developing a new way of thinking about disability; thus, changing commonly held beliefs and values and the practice of becoming reflective about their own actions and beliefs in the classroom (Forlin \& Sin, 2017). The skill of being able to critically reflect on one's practice has been touted as an important characteristic of an inclusive teacher (Darling-Hammond et al., 2017; Lui, 2013). Addressing prevailing attitudes to make teaching practice more inclusive is difficult to teach, however, challenging teachers to think reflectively about what they are doing and what the effect of their actions are, can help them gain insight into their own teaching practice. Enabling teachers to develop self-reflection skills is one method that can be taught as a purposeful 
exercise in changing attitudes. Teachers most often view critical reflection as taking a punitive look at their practice and then not knowing what to do with the result, while teacher educators tend to view critical reflection as a practice that challenges assumptions and beliefs and seeks to improve teaching practice and promote effective learning in the classroom (Liu, 2013). This process involves the teacher examining their current teaching practice, questioning their actions and the effect of those actions and then rethinking their actions in the light of having been exposed to new knowledge about teaching practice. Other researchers have also recommended that CPD courses on inclusive teaching practice should include training in critical reflection skills. Mezirow (1997) for instance, contends that the capacity to reflect deeply on one's own assumptions, values and beliefs can result in a fundamental change in practice. Critical reflection and the examining of the values and beliefs teachers hold about inclusion, disability and their own view of being an inclusive practitioner can be a valuable exercise leading to the improvement of their professional practice (Shandomo, n.d.; Smith, 2011). However, teachers find the concept of critical reflection difficult as it is easier to reflect on what others are doing than to reflect personally on their own motivation, assumptions and actions. Being a reflective teacher requires being able to be introspective but open-minded towards changing personal education practices and attitudes. Liu (2013) asserts that critical reflection is a complicated cognitive process and that teachers need support to able to develop this skill. Critical reflective feedback from in-service teachers can provide valuable insight into the experience and needs of teachers and can be an additional method of assessing the effectiveness of their learning after attending a CPD training course. Teachers who are able to reflect critically on their own sense of purpose in relation to their understanding of social justice, beliefs and attitudes towards diversity and their competency in inclusive teaching practices are better positioned to transform institutional structures and cultures (Pantic \& Florian, 2015). Developing this capacity is of particular interest in the South African context.

An approach described by Rouse (2008) and adapted by Florian (2012) in the Inclusive Practice Project at the University of Aberdeen may be considered useful in the training of inservice teachers to reflect critically on their inclusive pedagogy in South Africa. The premise being that for CPD courses to be successful in the changing of teachers' attitudes, it is important to consider the theory teachers need to know, what they are expected to do with this knowledge and what they believe about being inclusive practitioners. This approach sets out three aspects; that of 
knowing, doing and believing. For the purpose of this study, these aspects have been interpreted as in the discussion below.

Florian (2012) asserts that knowing, or head knowledge, refers to the teachers' understanding of the philosophy of inclusion, the appropriate legislation, and policies, what the different learning disabilities are and how to identify, assess and support learners who learn differently. This would constitute the theoretical component of a CPD training course. Doing, or hand knowledge, refers to teachers being able to implement the knowledge they have gained in practical ways to develop inclusive teaching strategies and enhance their practice. This component would consist of practical activities and demonstrations on how to become a more inclusive practitioner in the classroom. This would create a balance between theory and practice resulting in believing or heart knowledge. This in turn refers to a change in beliefs and attitudes whereby teachers realise that all learners can learn and need support and that they are capable of teaching learners with disabilities as they do possess the necessary skills and agency to respond to diversity in their classrooms (Rouse, 2008; Florian, 2012; Pantic \& Florian, 2015).

This research study formed part of a larger study which is aimed at proposing design principles for CPD training courses in inclusive teaching strategies. The focus of this study was on how a group of South African teachers perceived themselves as being inclusive practitioners after attending a CPD course in the form of a short learning programme on inclusive teaching. The study sought to ascertain the teachers' perspectives of themselves as competent inclusive practitioners in respect of possible changes in their attitudes towards learners with a wide range of learning needs and in feeling more equipped to teach and support all learners in a diverse classroom through a process of reflection. To this end, time was intentionally 'built in' to the programme and participants were encouraged to think about and reflect on what they had learnt and how it might impact on their classroom practice.

\section{Short learning programmes in inclusive classroom practice}

As learning-teaching techniques that work for inclusive practice is an important factor in the changing of attitudes of teachers, the University of Johannesburg (UJ) conducted short learning programmes (SLPs) in four South African provinces over a period of five years. The SLPs consisted of screening and identifying learners with barriers to learning, diagnostically assessing those learners and designing inclusive strategies to support them in the classroom as well as 
developing individualised educational support plans to target specific needs. The courses were designed around two, one-week sessions with the aim of balancing vigorous academic theory with practical usefulness. Universal Design for Learning (UDL) (CAST, 2018) principles were utilised as a foundation to present the SLPs which included content such as inclusive education, learning support, curriculum differentiation, collaborative teamwork, creating of resources and online learning. Participants were encouraged to reflect individually on their learning and the impact of that learning on their beliefs regarding learners with disabilities after completion of the course.

Participation in the programmes was voluntary, although due to budget constraints, only one participant per school was chosen by the Education Department officials in each province, with the stipulation that the chosen participants would cascade their learning to colleagues at their respective schools. The participants were all qualified teachers, largely female, accurately reflecting the gender composition of primary school teachers in South Africa, with the average age being between 41 and 50 years. Many of the participants chosen were from rural schools with few resources. The CPD courses were conducted in English, however the cultural background and the languages spoken differed in each province, with some provinces showing more diversity in this regard than others. Code switching was permitted for clarity and understanding of the concepts being discussed, but for many of the participants English was their second or third language. Hence the verbatim quotes reflect the authentic responses of the participants even though the English grammar may not always be correct. Ethical clearance (SEM 1 2019-014) was obtained from the Ethics Committee of the Faculty of Education at the University of Johannesburg. Informed written consent for the taking of photographs and the use of personal reflections was obtained from each person who participated in this study. Participants were also free to choose whether to participate in the research activity or not (Ramrathan et al., 2017).

\section{Research design and method}

This was a qualitative interpretive research design rooted in phenomenology as this approach attempts to explore and understand people's behaviour, attitudes and beliefs in regard to a particular phenomenon and their own specific social reality (Cresswell, 2014, Haradhan, 2018, Nieuwenhuis 2020). Phenomenology is concerned with the investigating of the lived experiences of individuals of a particular phenomenon from their personal perspective. Moreover, it is an 
attempt to determine the meaning the individual ascribes to their experience. This approach was chosen as it seeks to gain insight into the participants' experiences, beliefs and perceptions of themselves as inclusive teachers. As qualitative research is usually inductive in nature; the purpose of this study was to describe the meaning the teachers attending the CPD course attributed to themselves as inclusive teachers. The data collected was analysed manually with codes being assigned to data segments. These codes were then used to identify common essential themes to develop a composite description of the essence of the meanings of the teachers' perceptions of themselves as inclusive teachers (Cresswell, 2014, Nieuwenhuis, 2020). In this study the thematic findings from the data analysis were contrasted and compared to the 'head, hand and heart' approach described by Rouse (2008) and Florian (2012) to confirm the effectiveness of the learning achieved during the CPD courses in changing the beliefs and attitudes of teachers in implementing their theoretical knowledge.

In qualitative research, data collection can take many forms including group or individual interviews, analysis of photographs, videos, artefacts and even art work (Van der Vaart et al., 2018). In this study two methods of data collection were used to determine the participants' attitudes in relation to inclusion and their views of themselves as teachers in diverse classrooms.

The first set of data collected was that of clay symbols. Participants were given a small lump of clay and asked to use the clay to make a symbol that best represented their view of themselves as inclusive teachers. Photographs were taken of the symbols made during each training session. Open coding was used to put the symbols into categories according to what they represented (Nieuwenhuis, 2020). In the first iteration during the first two CPD courses, participants were asked to make clay symbols and were then asked why they had chosen a specific symbol. In the following six CPD courses where participants were asked to reflect on themselves as inclusive practitioners by making clay symbols, they were also asked to write an explanation of why they had chosen to represent themselves with a particular symbol. The symbols were categorised according to what they represented, however the meanings that accompanied each symbol were further categorised into different themes. In a second analysis these themes were then compared to the head, hand or heart knowledge metaphors.

Findings: Clay symbols characterising an inclusive teacher 
A total of 328 clay symbols from eight different CPD training courses were analysed. It must be noted that many of the participants found it difficult to symbolise themselves as inclusive teachers, with some being quite hesitant at first to work with the clay. Therefore, after the first two workshops, critical self-reflection was explained as being the process of thinking about what an inclusive teacher is and how they could describe themselves as inclusive teachers using the characteristics of different symbols. A practical example was shared with the participants to stimulate the process. Participants were also urged to discuss their ideas in groups before making their symbols. After the drying process, photographs were taken of the different symbols. This was done as the participants were encouraged to take their symbols home as a reminder of what they had learnt about themselves and becoming more inclusive in their practice on the course.

The clay symbols were categorised into groups such as shapes, objects, animals, celestial bodies and nature. Most of the participants made unsophisticated representations such as pots, snakes and different shapes but there were some that displayed an ability to fashion more detailed symbols. However, of greater interest was the meaning attached to the symbol and not the artistic merits of it. The number in brackets serves to identify the specific CPD course and participant while upholding the confidentiality of the participant. The explanations of the symbols ranged from uncomplicated short phrases to extended metaphors with deeper meanings.

The majority of symbols represented some form of light generation. Celestial bodies such as the sun, moon and stars were made in different forms as were candles, lamps, light bulbs, torches and flashlights. The meanings attached to these symbols were given as variations of "I bring light to all learners (PC1a18)"; "I represent light and knowledge (PC1a16)"; "I bring light and hope to all learners with disabilities (PB3-29)"; "as a candle that shines in the dark I give hope and I see clearly where others don't see, I am able to identify barriers that others cannot(PB3-19)"; "I bring light to the learners so they can reach their potential (PC2a33)" and "I give light to the whole community PC2a28).”

A second common symbol was that of a pot, bowl or calabash. This symbol was related to food with food being a metaphor for knowledge and sustenance. This was illustrated by comments such as "I provide food for different learners (PB4-22)" and "I give food and feed my learners with 
good education and accommodate all learners irrespective of physical and learning challenges (PB5-3).”

Another very commonly depicted symbol was that of a heart shape in different forms. The meanings attached to this symbol related more to love for all learners and acceptance of diverse learners despite any disabilities. This was shown by comments such as "love is all we need; I have a big heart with enough room to accommodate all the different learners (PB3-30)"; "I have an open heart for all children irrespective of their differences (PC2a19)"; "to always treat each learner with love and respect (PC2a62)"; "to always have a positive attitude to the learner (PB4-25)"; "a good heart to learners will make the difference in the learner (PB4-34)" and "I am a symbol of love to my learners that accommodates everyone (PB5-6)."

Symbols representing hands were fairly common with hands being described as "helping hands to learners who are struggling (PD2b2)"; "to catch them with, to hold them with, to make them feel safe (PC2a65)" and "I am moulding children's minds (PB2-14)."

Some participants presented symbols which included different people, objects, animals, shapes, places and plants. These symbols were accompanied by a more detailed metaphorical explanation.

Animal symbols presented alluded to the characteristics of the animals. A participant symbolised herself as a sheep, explaining that "the wool represents my knowledge which I always impart to (sic) all learners. I make sure every learner feels warm in my class. I don't shout to those struggling learners but I bring them close to me so that they can learn easily. I don't complain about workload (PB3-26)." Another participant symbolised himself as an elephant being the image of a wise teacher who is "always thinking of strategies and approaches to all learners, emphasising the value of a teacher and the importance of a child (PC1a12)." The symbol of a lion was presented with the comment: "I choose every child's insecurities like a lion that pretends to be hurt by their young's bite in order to motivate them and make them aware of their abilities (PB4-7)." A symbol of an eagle was presented with the comment: "[an eagle] can use her 5 layers in her eyes to help learners with difficulties. If I fail to help then I will go back to find help on how to do it like the eagle when she sharpens her beak (PB4-8)."

Other symbols included a seated figure such as the famous stature of the thinker by Auguste Rodin which was presented with the comment that "teachers must think deeply about the learners 
and find ways to help (PB2-33)." A few participants further depicted different variations of roots for plants or trees. One participant stated: "I'm strong to hold all the learners as leaves or branches. Nurturing, loving, empowering them, always there for them whatever the need (PC2a42)" and "anchoring the plant body to the ground and supporting it (PC2a43)."

Unique symbols presented by singular participants included a padlock to "unlock the minds of the learners irrespective of the challenges they might have. Education is the key to everything (PB4-6)"; a chain symbol depicting "that we are all linked together and must work as a team (PD2b1)"; a saucer with the description: "I carry a cup and a teaspoon, if the tea spills it falls on me even if the spill is caused by me stirring. The cup I carry represents teachers and the spilling tea represents learners who are not accommodated in the lesson. I shall carry them with my inclusive education differentiation (PB3-27)"; a crossroads symbol with the comment: "this shows that you are exposed to choices and must choose which way you will go (PD2b3)"; another made a symbol of an axe and explained in this way: "for me to work well I need to be well sharpened (PB3-23)"; a mini bus taxi, a typical mode of transport all over South African, was commented on as: "I always carry my learners to where they need to be. When one is ready to get off, I pick up the next one as there's always place for one more (PC2a50)"; a car with the comment: "I can carry light and heavy loads, I am powerful. All learners with barriers can be scaffolded from lowest level to highest level. I have different parts that move me to different directions. I'm in different shapes and colours to accommodate different levels of barriers (PC2a56).”

To give a more balanced view of the teachers' beliefs and attitudes about themselves as inclusive practitioners, a second set of data was analysed. At the end of each CPD training course, a feedback activity was done to gauge perceptions of the learning that had occurred during each of the workshops. Participants were encouraged to write personal reflections on the course and their personal learning.

\section{Findings: Feedback activity on personal learning}

These written reflections were analysed and comments relating to their views of themselves as inclusive practitioners were systematically interpreted using thematic analysis to identify common categories (Nieuwenhuis, 2020). These categories were then related back to the head, hand or heart 
knowledge metaphors described by Florian (2012). From the analysis of these reflections two broad themes emerged each with several sub-themes.

\section{New knowledge}

The first theme was knowledge gained, illustrated by comments such as: "I acquired new knowledge (PC1a101)" and "I've learnt a lot of things (PB4r10)." However more detailed comments elaborated further on the type of knowledge gained.

For instance, knowledge gained (head knowledge) was linked to a deeper understanding of education policies in South Africa: "equipped with more knowledge about inclusive education (PC1a2)"; learned a lot about SIAS [Screening, identification, assessment and support policy] which is a very important aspect of inclusion (PC1a62)"; "knowing what is inclusive education (PB2r12)"; "learning about curriculum differentiation (PB2r28)"; "inclusivity is not a giant phenomenon (PC1a60)" and "it opened a window in my mind which was closed about inclusive education (PC1a16)."

Knowledge gained was also extended to supporting learners within the classroom: "how to help learners with disability (PB2r17); "all learners can learn only if they are accommodated and supported (PB3r5)" and "understanding the learner's barriers and knowing how to support them (PB5r26)."

Closely associated with the facet of support was that of learning strategies to use when supporting diverse learners in the classroom (hand knowledge): "as long as you plan, assess and report you will know where your support is needed (PC1a1)"; "now we have learned the strategies of helping them (PB2r32)"; "different strategies on how to teach the 4 modalities in language (PB2r14)" and "I learn about the assessment methods (PC1a11)."

Strategies learnt was further elaborated on and described as practical skills that were associated with the different strategies learnt: "I was empowered in skills on making various LTSM [learning and teaching support materials] (PB2r45)"; "I liked the new ideas of introducing a lesson by using teaching aids (PB3r54)"; "learned how to recycle used material to use them for teaching as cost-effective learning material (PB5r15)" and "I have learned about uploading in the website (PB5r16).” 
The last sub-theme that emerged under knowledge was that of collaboration and working as a team: "we learn to work as a group and the importance of collaboration (PC2a65)"; "I've learnt more about teamwork (PB3r7)" and "there was a lot of creativity that I learn from my colleagues (PB2r4).”

\section{Changed attitudes}

The second theme was related to attitudes that had become more positive about inclusive teaching (heart knowledge). This was seen in variations of comments such as: "now I'm happy because I'm going to teach learners well (PB2r11)" and "makes me feel how wonderful being a teacher is (PC1a1)." This second theme was also broken down into a number of sub-themes.

The change in attitude was also reflected in comments that related to a renewed confidence in their own abilities as teachers: "learnt a lot and feel more confident and competent in my work (PB4r25)"; "given me confidence I will be able to support educators and assist them on how to deal with learners with barriers (PB3r20)" and "I am better equipped and skilled in how to handle children with barriers (PB3r57)."

The renewed confidence in teaching learners with barriers was in turn linked to a change in attitude towards learners with barriers in the classroom. This sub-theme revealed the most detailed comments about a change in attitude: "I also got information that each learner is unique, I must treat them as such, these kids are also humans who have dignity in our society (PC1a64)"; "I have a revival of willingness to help LSEN [learners with special education needs] (PC1a94)"; "all the learners have a right to learn with other children (PB2r48)"; "it is not correct to treat all learners as that they have equal capability (PB3r1)"; "it instilled transformation and willingness to work irrespective of the challenges experienced at schools (PB3r14)"; "I have discovered how we usually disconsidered [sic] the potentiality of learners when teaching as educators. The course unlocked my understanding of teaching challenged learners and the support needed for such learners (PB3r15)."

Attitudes were linked to improved teaching practice: "a change of attitude towards it as I learnt new skills of dealing with problems in the classroom (PC1a6)"; "it helped me to develop interest to gain knowledge and acquired knowledge about how to teach the underachievers at 
school (PB2r23)"; "I learned about interesting ways of teaching (PB2r47)" and "learnt how to accommodate all learners in a school environment (PB5r33)."

Improved teaching practice was closely linked to an attitude where teachers were more willing to implement inclusive teaching practices: "they capacitated me a lot on implementing the inclusive education in my school (PC1a13)"; I'm ready to deliver and implement information I got from the whole programme (PC1a24)"; "improved my attitude in implementing strategies of inclusive education and putting the knowledge into practise (PB3r46)" and "sharing ideas and being creative (PB2r43).”

\section{Discussion of the findings}

Critical reflective thinking is widely held as being the ability to think about what one is doing and what the effects of that action are. It has also been described as a way of improving professional practice across the social sciences by examining beliefs and professional identity rather than just reiterating theoretical knowledge (Smith, 2011). This study sought to investigate teachers' perspectives of themselves as inclusive practitioners and whether their attendance at a CPD course had influenced their perspectives. In particular, to gauge whether the CPD course had had an effect on the beliefs and attitudes of the participants and their understanding of their role as an inclusive teacher in impacting learner achievement in the classroom. Hence participants were encouraged to reflect critically on their own learning in different tasks. Critical reflection seemed to be a new concept to many teachers with a number of the participants having difficulty being able to reflect critically on their own practice. This finding was also mooted by Makoelle (2012) who stated that the practice of reflection was one that needed to be developed in South African teachers. A number of participants opted not to make a symbol but rather to just "play with the clay." Much of the feedback was written more from the viewpoint of what the participant enjoyed about the course rather than what they had personally learnt. However, the results provided some encouraging evidence that participants are beginning to think more critically about their role, challenge their beliefs and assumptions about their knowledge and change their attitudes towards teaching in a classroom with a wide range of diverse learning needs.

\section{Head, heart, hand knowledge?}

All three of these elements were echoed in both the personal reflections and the clay symbols to a greater or lesser degree. Each of these facets of knowledge are closely interlinked and influence 
each other. Clay symbols and written reflections often combined two or more of the facets embedded in the meanings depicted. Many of the clay symbols that were made represented common items in the South African context and were similar across all provinces. Some of the clay symbols were accompanied by a simple but profound explanation while others represented an extensive metaphorical narrative. What was of interest was the pragmatic and deeper metaphorical meanings attached to the symbols as used to describe personal perspectives of being an inclusive teacher. Different symbols often represented the same meanings. However, most of the written personal reflections were not critical reflections but more appraisal comments. Those that were actual personal reflections were honest and revealing, exhibiting a willingness to change their teaching practice to enhance learning and promote social justice practices for all learners. This confirms the sentiment that critical reflection is part of the growth process and should be engaged in regularly in collaboration with colleagues to evaluate and make appropriate changes to improve inclusive teaching practice (Makoelle \& van der Merwe, 2014).

Theoretical knowledge pertaining to inclusion, inclusive education policies and legislation and identifying, assessing and supporting learners with diverse needs were all mentioned in personal deliberations. The responses revealed that some participants had acquired new knowledge around different aspects of inclusion. Moreover, others who had prior theoretical knowledge about inclusion revealed that they had not really understood it and had not known how this knowledge should impact their practice. They described a better understanding of the precepts of inclusion as well as policies such as the SIAS document (DBE, 2014) and how to complete it. These findings are in line with those of previous research which states that whereas teachers have accepted the idea of inclusion, that knowledge had not translated into change in teaching practice in the classroom.

This deeper understanding of inclusion and related education policies led to a realisation of the need for inclusive strategies to be implemented to meet the needs of diverse learners. This was reflected in comments relating to abilities to identify and assess learners with barriers to learning. This phenomenon was observed in the meanings behind many of the clay symbols where the participants had made symbols relating to food, light and even some of the animal symbolism. Light was used in the sense of giving knowledge and direction and food as an analogy of sustenance for growth. This symbolism revealed the knowledge the participants now felt they 
possessed in order to be able to support all their learners and teach them despite their different learning needs.

The heart symbol which was made by many participants across all the CPD courses was most encouraging. The heart is a common analogy for love. In the accompanying explanations of this symbol, participants expressed their 'love' for learners with different abilities signifying an acceptance of difference and an understanding that as teachers they could support these learners in particular. The written personal reflections confirmed this acceptance in comments that were made about the different barriers to learning and inclusive support strategies that they could use in the classroom. Most gratifying was the expression of feeling more confident in their abilities to manage diverse classes and include all learners in teaching and learning activities. This confidence in personal agency also extended to being able to assist colleagues who were not on the training course. The idea of being part of a team and collaborating with other teachers was also observed in the written reflections adding to the sentiments represented by the clay symbols.

The personal narratives created by some of the participants when making the clay symbols were of particular interest as they revealed a more in-depth self-reflection. Characteristics of particular animals such as the sheep, eagle and lion and other everyday items such as the taxi and the saucer, told stories of teachers who were indeed combining head, hand and heart knowledge to become more inclusive practitioners. Therefore, asking participants to make a symbol representative of themselves in reflecting on their own teaching practice appeared to be more successful than just writing a personal reflection. We live in an increasingly visual world and much of our social reality can be organised more readily in a visual form making it easier to reflect on and then write about (Bagnoli, 2009). Creswell (2014) notes that visual images together with written explanations allows access to different parts of human consciousness and thus a person's perceived reality which more traditional methods of data collection might miss. Inferences about social reality can be made unobtrusively and used as indicators of social activity and beliefs (Emmison \& Smith, 2000). These observations can then be confirmed by more traditional data collection methods.

\section{Limitations of the study}

It was not possible to determine long-term changes because of the number of participants and the large geographical area they represent. Thus, while education department officials affirmed that 
the participants on the CPD courses had learnt a lot, it was not possible to follow-up to find out how the participants view of themselves as inclusive practitioners had changed after the training course or whether changes in attitude were sustained after their return to their respective schools. The CPD training courses although based on international best practice were specific to the South African situation and may not be able to be generalised to other cohorts of teachers.

\section{Conclusion and Recommendations}

Educational change can be challenging to one's beliefs about one's profession. Having to teach inclusively is very different to teaching in the traditional way. It requires an understanding of the philosophy of inclusion, a willingness to adapt teaching methodologies and a paradigm shift in personal attitudes and beliefs to be able to successfully include learners with a wide range of learning abilities and needs in general education classrooms.

CPD has been described as "a planned, continuous and lifelong process whereby teachers try to develop their personal and professional qualities, and to improve their knowledge, skills and practice, leading to their empowerment, the improvement of their agency and the development of their organizations and their pupils" (Padwad \& Dixit 2011, p.7). To be able to do this, teachers need to use an effective framework for inclusive practice which benefits learners and increases their capacity and confidence in being able to teach learners with different disabilities. As teachers have found this challenging, a constructive CPD course on inclusive education should incorporate a balance between head, hand and heart knowledge in its conception to enable teachers to become effective agents of change. Teachers who have been trained in inclusion and who value diversity and respect the rights of learners with disabilities are able to change their attitudes and successfully develop good inclusive teaching practices.

Critical personal reflection is an important skill for teachers to develop to be able to change their practice in line with current educational thinking and become inclusive practitioners. Critical personal reflection or being able to think critically about one's practice is essential for teaching inclusively and should be actively encouraged. The ultimate purpose of critical reflection should always be to enhance the learning of the learners in the classroom but at the same time encouraging the teacher to challenge their beliefs and attitudes towards diverse learners (Liu, 2013). Schools in South Africa as social institutions are based on the principles of human rights and social justice. 
Schools and teachers therefore have a role to play in the transforming of their communities to become more just and inclusive, and accepting of difference. This can only be done if teachers are able to critically reflect on their practice, change their actions to enhance learning and promote social justice practices for diverse learners (Liu, 2013). As most of the teachers in this study had difficulty in being reflective about their practice it is recommended that this skill is actively modelled and taught during CPD courses on inclusion.

Visual images such as the making of clay symbols is a useful technique in developing critical reflective skills. Teachers in this study were able to fashion a symbol which represented their perspectives of themselves as inclusive practitioners. Symbols such as a star, a heart, a candle, a calabash and even a taxi represented meanings about their lived social reality as well, if not better, than an answer on a questionnaire.

The use of visual images in the data collection process proved to be additional facet to understanding teacher attitudes and enhanced the findings in this study. The use of visual images through different art forms needs to be explored more as a technique for making inferences based on what participants actually think and do. Visual images can aid the researcher to test whether their speculative inferences are valid and can enhance the findings of more traditional data collection methods (Emmison \& Smith, 2000). The use of creative images facilitates the exploring of multiple layers of meaning which often times participants of all ages may find difficult to express in words (Bagnoli, 2009). This is because images allow for metaphorical communication and the interpreting of social reality from a different perspective. Being able to critically think about one's practice is an essential skill for teaching inclusively. In this study the making of clay symbols encouraged critical personal reflection among practising teachers. The value of this research design is that it was conducted in real-life situations and is therefore context-bound while still providing a rich description of the underlying beliefs and values of the participants and at the same time remaining sensitive to cultural influences (Haradhan, 2018).

The role of inclusive teachers encompasses being able to effectively support learners with diverse learning needs through the development of inclusive teaching practice and strategies thus improving overall achievement. Moreover, this role also comprises the development of social justice, the creation of an inclusive environment, collaboration with all stakeholders and the development of their capacity to reflect on their own inclusive practice (Engelbrecht, Nel, Nel, \& 
Tlale, 2015; Guskey, 2002; Pantic \& Florian, 2015). Without the 'buy in' of teachers, the creation of a more inclusive and equitable education system that could reasonably accommodate all learners would not be possible. It has been asserted that in combination with providing teachers with the necessary knowledge and skills to become more inclusive in their practice, it is just as important to instil the appropriate beliefs and attitudes to realise a commitment to teaching inclusively (Forlin \& Sin, 2017; Nel et al., 2016). Education authorities can develop and legislate changes in policy but it is far more difficult to change the existing attitudes of in-service teachers (Madikana et al., 2007). The attitudes of in-service teachers and their beliefs around inclusive practices within their own schools and classrooms is one of the most important factors to consider when planning CPD training courses in inclusive education. Moreover, the attitude of teachers' towards implementing inclusive practices in their classrooms is also influenced by their peculiar systemic contextual factors (Engelbrecht, Nel, Nel, \& Tlale, 2015). High quality CPD courses should consider the context of the cohort of teachers attending a specific CPD course and ensure that the content being presented is pertinent to that context if the training is to be successful in changing the attitudes of in-service teachers (Darling-Hammond et al., 2017).

\section{Declaration}

This study received a specific grant as part of the Teaching and Learning Development Capacity

Improvement Programme, which is implemented through a partnership between the South African Department of Higher Education and the European Union.

Elizabeth Hooijer is a specialist in Remedial and Inclusive teaching strategies. She is involved in the teaching and supporting of learners with barriers to learning and their teachers in mainstream schools. She has worked as an assistant lecturer in the training of remedial teachers and learning support educators. Her research interests lie in the field of inclusive education and learning support in diverse classrooms. She has presented papers at international and national conferences on learning support strategies in inclusive classrooms. 
Dr van der Merwe is involved in the teaching of the Post Graduate Certificate in Education, the Advanced Diploma in Remedial Education, the Post Graduate Diploma in Inclusive Education, the Honours in Inclusive Education, as well as the Masters in Educational psychology programs. He is a teacher educator who firmly believes that who the teacher is, is more influential than what the teacher knows in educational interactions. Interactions based on invitational and authentic relationships form the core of his beliefs. His research interests are located in particularly the inclusive pedagogies and strategies that teachers use to facilitate equitable learning spaces. A further interest lies in the teacher disposition and the identification and development of such dispositions for the changing teaching profession. These interests are grounded in a critical realist position in ascertaining the structural factors which may facilitate or constrain the agency of newly qualified teachers to act as change agents in the teaching profession.

Dr Jean Fourie is an Educational Psychologist who lectures at the University of Johannesburg in the Faculty of Education. She is involved in the training of Educational Psychologists; school counsellors and remedial teachers. Her research focuses on inclusive education and learning support. She has worked extensively in special needs education. She has presented papers at international and national conferences on supporting children with neurodevelopmental disorders.

\section{References}

Braunsteiner, M. (2016). Implementing the index for inclusion for inclusive schools: A new paradigm. Open online Journal for Research and Education. Special issue \#5. ISSN: 23131640. https://journal.ph-noe.ac.at.

Bagnoli, A. (2009). Beyond the standard interview: the use of graphic elicitation and arts-based methods. In Qualitative Research, 9(5) p 547-570 http://dx.doi.org/10.1177/1468794109343625

CAST (2018). Universal Design for Learning Guidelines version 2.2. http://udlguidelines.cast.org 
Creswell, J. W. (2014). Research design. Qualitative, quantitative and mixed methods approaches. (4th ed.), SAGE Publications.

Dalton, E.M., Mckenzie, J.A., Kahonde, C., (2012). The implementation of inclusive education in South Africa: Reflections arising from a workshop for teachers and therapists to introduce Universal Design for Learning. in African Journal of Disability, 1(1). https://www.researchgate.net/publication/233902360.

Darling-Hammond, L., Hyler, M. E., Gardner, M. (2017). Effective Teacher Professional

Development. Learning Policy Institute. https://learningpolicyinstitute.org/product/teacher-prof-dev.

Department of Basic Education (DBE). (2016). Implementing inclusive education in South Africa 2001-2016. [PowerPoint slides]. https://www.enspired.net/sites/default/files/uploadedfiles/20161024_dbe_sa_education_system.pdf

Department of Basic Education (DBE). (2014). National Strategy on Screening, Identification, Assessment and Support.

Department of Education (DOE). (2001). Education White Paper 6. Special Needs Education: Building an Inclusive Education and Training System. Government Printer.

Dreyer, L.M. (2017). Inclusive education in Ramrathan, L., Le Grange, L. \& Higgs, P. (Eds). (2017) Education studies for initial teacher development. Juta ISBN 9781485102663.

Donohue, D, \& Bornman. J. (2014). The Challenges of Realizing Inclusive Education in South Africa. South African Journal of Education, 34(2),1-14.

Emmison, M. \& Smith, P. (2000). Researching the Visual. Images, Objects, Contexts and Interactions in Social and Cultural Inquiry. SAGE publications.

Engelbrecht, P. Nel, M. Nel, N., \& Tlale D. (2015). Enacting Understanding of Inclusion in complex contexts: Classroom Practices of South African Teachers. South African Journal of Education, 35 (3).

Engelbrecht, P., Nel, M., Smit, S., \& Van Deventer, M. (2015). The idealism of educational policies and the realities in schools: The implementation of inclusive education in South 
Africa. International Journal of Inclusive Education, 20(5), 520-535. https://doi.org/10.1080/13603116.2015.1095250

Florian, L. (2012). Preparing teachers to work in inclusive classrooms: key lessons for the professional development of teacher educators from Scotland's Inclusive practice project. In Journal of Teacher Education, 63(4), 275 - 285.

Forlin, C. \& Sin, K. (2017). In-service teacher training for Inclusion. Professional Learning and Development Educational Systems Online publication March 2017. https://doi.org/10.1093/acrefore/9780190264093.013.161

Guskey, T.R., (2002). Professional Development and Teacher Change. In Teachers and Teaching Theory and Practice, Vol 8(3), 381-391, DOI: 10.1080/135406002100000512

Haradhan, M.K., (2018). Qualitative research methodology in social sciences and related subjects. In Journal of Economic Development, Environment and People, 7(01), 23- 48. https://mpra.ub.uni-meunchen.de/85654/

Hehir, T., Grindal, T., Freeman, B., Lamoreau, R., Borquaye, Y., \& Burke, S. (2016). A summary of the evidence on Inclusive education. Abt Associates.

Liu, K., (2013). Critical reflection as a framework for transformative learning in teacher education. In Educational Revie, Vol 67(2), 135 - 157. https://doi.org/10.1080/00131911.2013.839546

Madikana, A., Ntshangase, S., \& Mayekiso, T. (2007). Pre-service educators' attitudes towards inclusive education. In International Journal of Special Education, Vol 22(1), 125-131.

Makoelle, T.M. (2012). Analysing the use of action research to develop practices of inclusion: A case of a South African school. in Journal of Sociology and Social Anthropology, 3(2), 8391.

Makoelle, T. \& Van der Merwe, M.P. (2014). Educational Change and Inclusion: Lessons from A Collaborative Action Research. In Mediterranean Journal of Social Sciences, 5(14): 169179. http://DOI:10.5901/mjss.2014.v5n14p169.

Mezirow, J. (1997). Transformative Learning: Theory to Practice. In New directions for adult and continuing education. (2002). Jossey-Bass Inc. 74, 5-12. https://doi.org/10.1002/ace.7401 
Muzata, K.K. (2021). Special and Inclusive Education Provision in the Zambian Context. Lusaka, UNZA Press.

Muzata, K.K. \& Ndonyo, T.M. (2019). “'The Practice based Model: A Proposed Training Package for Special Education Trainee Teachers in Zambia' In: M.K. Banja (ed.). Selected Readings in Education Volume 2 (pp. 23-41), Lusaka: Marvel Publishers.

Nieuwenhuis, J. (2020). Analysing qualitative data. In K. Maree. (Ed.). First steps in research. (pp.118-155). Van Schaik.

Nel, N.M., Tlale, L.D.N, Engelbrecht, P., \&, M, (2016). Teachers' perceptions of education support structures in the implementation of inclusive education in South Africa. KOERS - Bulletin for Christian Scholarship, 81(3). Available at: https://doi.org/10.19108/KOERS.81.3.2249.

Oswald, M. \& Swart, E. (2011). Addressing South African Pre-service Teachers' Sentiments, Attitudes and Concerns Regarding Inclusive Education. International Journal of Disability, Development and Education, 58(4), 389-403. http://doi.org/10.1080/1034912X.2011.626665.

Pantic, N. \& Florian, L. (2015). Developing Teachers as Agents of Inclusion and Social Justice: Education Inquiry, 6(3), 333-351

Padwad, A. \& Dixit, K. (2011). Continuing Professional development: an annotated bibliography. British Council India. Available from www.britishcouncil.in/programmes/englishpartnerships.

Ramrathan, L., Le Grange, L., \& Shawa, L. B. (2017). Ethics in educational research. In Ramrathan, L., Le Grange, L. and Higgs, P. (Eds.). Education studies for initial teacher development. (pp. 432-443) Juta. ISBN 9781485102663.

Rieser, R. (2013, July 4-6). Promoting inclusive education for PWD. A framework to implement Article 24 around the world. [Paper presentation]. SAALED Professional Development Conference: Dismantling exclusion to enable Inclusion. Johannesburg.

Rouse, M. (2008). Developing inclusive practice: a role for teachers and teacher education? In Education in the North, 16, 6-11. 
Shandomo, H. M. (n.d.). The role of critical reflection in teacher education. School-University Partnerships, 4(1), 101-113. https://files.eric.ed.gov/fulltext/EJ915885.pdf

Smith, E. (2011). Teaching critical thinking. In Teaching in Higher Education, 16(2) DOI: 10.1080/13562517.2010.515022

Swart, E., Engelbrecht, P., Eloff, I., \& Pettipher, R. (2002). Implementing inclusive education in South Africa: Teacher's attitudes and experiences. Acta Academica, 2002 34(1),175 - 189.

Van der Vaart, G., Hoven, B., \& Huigen, P.P. (2018). Creative and Arts-Based Research Methods in Academic Research. Lessons from a Participatory Research Project in the Netherlands. Forum Qualitative Sozialforschung / Forum: Qualitative Social Research, 19(2), http://dx.doi.org/10.17169/fqs-19.2.2961.

Walton, E. (2010). Getting inclusion right in South Africa. In Intervention in School and Clinic, 46: 240 DOI: 10.1177/1053451210389033 http://isc.sagepub.com/content/46/4/240. 